\title{
Effect of vitamin D levels on radiographic knee osteoarthritis and functional status
}

\author{
Bedriye Mermerci Başkan, Fatma Gül Yurdakul, Ezgi Aydın, Filiz Sivas, Hatice Bodur \\ Department of Physical Medicine and Rehabilitation, Ankara Numune Training and Research Hospital, Ankara, Turkey
}

Received: October 18, 2016 Accepted: December 26, 2016 Published online: April 04, 2017

\begin{abstract}
Objectives: This study aims to investigate the effect of serum levels of 25 hydroxyvitamin D $(25(\mathrm{OH}) \mathrm{D})$ in patients with primary knee osteoarthritis (OA) and to assess its relationship with the radiographic grading and functional status.

Patients and methods: Serum 25(OH)D levels were measured in 107 patients (90 females, 17 males; mean age $63.0 \pm 9.6$ years; range, 40 to 86 years) with primary knee OA. Radiographic grading was based on the Kellgren-Lawrence Grading Scale and the Osteoarthritis Research Society International (OARSI) Atlas Grading Scale, while the functional status was assessed using the Lequesne indices and Turkish version of the Knee Injury and Osteoarthritis Outcome Score-Physical Function Short-Form (KOOS-PS). Pain was evaluated using the Visual Analog Scale for Pain (VAS-Pain). Data including age, sex, disease duration, body mass index (BMI), and pain severity were recorded.

Results: The mean 25(OH)D level was $13.4 \pm 10.6 \mathrm{ng} / \mathrm{mL}$, and 90 patients $(84.1 \%)$ had vitamin D deficiency. The presence of severe osteophytes was observed in 67 patients (62.6\%) and 85 patients (79.4\%) had Grade 2-3 joint space narrowing (JSN). The mean KOOS-PS and Lequesne scores were $40.1 \pm 12.3$ and $12.9 \pm 3.6$, respectively. There was no correlation between serum $25(\mathrm{OH}) \mathrm{D}$ levels and functional status.

Conclusion: Our study results show that serum $25(\mathrm{OH}) \mathrm{D}$ level is not related to the severity of the radiographic knee OA grading or to the functional assessment. Age and BMI are the factors affecting the radiological knee OA severity, while age, sex, BMI, and pain severity are the main determinants of the functional status.
\end{abstract}

Keywords: Functional status; knee osteoarthritis; radiographic grading; vitamin D.

Osteoarthritis (OA) is a disease of all elements of the synovial joints, while the mainly affected components are cartilage and subchondral bones. It is known as the most common cause of functional failure in elderly. Although the pathogenesis of the disease is not clear, there are molecular evidences about the coordinated release of cytokines and inflammatory mediators from elements of synovial joints. Various risk factors such as mechanical stress, biochemical abnormalities, genetic predisposition, and metabolic disorders have been suggested for the progression of OA..$^{[1,2]}$

Vitamin D is a steroid hormone which plays a central role in calcium and phosphorus metabolism and bone mineralization. ${ }^{[3]}$ Normal bone metabolism is related with the presence of vitamin $D .{ }^{[4]}$ In recent years, insufficient levels of vitamin $\mathrm{D}$ has been shown to be associated with many chronic diseases, including common cancers, cardiovascular diseases, metabolic syndrome, autoimmune diseases, changes in cartilage composition, subchondral lesions, and progression of knee OA. ${ }^{[3,5]}$

There are many studies about the association between serum 25 hydroxyvitamin D $(25(\mathrm{OH}) \mathrm{D})$ deficiency and knee OA. Previously, a significant association between $25(\mathrm{OH}) \mathrm{D}$ with knee OA has been reported. $^{[5]}$ It has been also suggested that serum $25(\mathrm{OH}) \mathrm{D}$ should be measured in any patients with symptoms suggestive of knee OA, particularly at the initial stage of disease. ${ }^{[5]}$ However, the level of $25(\mathrm{OH}) \mathrm{D}$ seems not to be related to the severity of the radiographic knee OA grading, cartilage loss, or functional assessment in knee OA..$^{[6,7]}$

Corresponding author: Bedriye Mermerci Başkan, MD. Ankara Numune Eğitim ve Araştırma Hastanesi Fiziksel Tıp ve Rehabilitasyon Kliniği, 06100 Altındağ, Ankara, Turkey. e-mail: bmbaskan@gmail.com 
In the present study, we aimed to investigate the effect of serum levels of 25(OH)D in patients with primary knee $\mathrm{OA}$ and to assess its association with the radiographic grading and functional status of the patients.

\section{PATIENTS AND METHODS}

This cross-sectional study included a total of 107 patients (90 females, 17 males; mean age 63.0 \pm 9.6 years; range, 40 to 86 years) who were admitted to our Physical Medicine and Rehabilitation outpatient clinic and were diagnosed with primary knee OA between March 2015 and September 2015. The diagnosis of primary knee OA was based on the American College of Rheumatology (ACR) criteria. ${ }^{[8]}$ Patients with inflammatory arthritis, intra-articular neoplasms, osteonecrosis, trauma, paresis, neuropathy, mental disorders, history of previous knee surgery, and history of intra-articular intervention or physical therapy within the past six months were excluded from the study. All patients included were informed about the study, and their written informed consent was obtained. The study protocol was approved by the institutional Ethics Committee. The study was conducted in accordance with the principles of the Declaration of Helsinki.

Demographic characteristics including age, sex, and disease duration were recorded. In both knees, the range of motion (ROM) was measured by goniometry and anteroposterior and lateral knee radiographs were taken during weight-bearing. Radiographic grading of $\mathrm{OA}$ was performed according to the Kellgren-Lawrence (K-L) criteria ${ }^{[9]}$ by an experienced radiology specialist. All patients were scored for joint space narrowing (JSN) and osteophytes separately on a scale from 0 to $3(0=$ normal; $3=$ severe $)$ according to the Osteoarthritis Research Society International (OARSI) Atlas. ${ }^{[10]}$ Pain was evaluated using the Visual Analog Scale for Pain (VAS-Pain), $0-10 \mathrm{~cm}$ and the severity of pain was assessed. ${ }^{[11]}$ All patients were also assessed for function using the Lequesne indices $^{[12]}$ and Turkish version of the Knee Injury and Osteoarthritis Outcome Score-Physical Function Short-Form (KOOS-PS). ${ }^{[13]}$

Intact parathyroid hormone (PTH) (reference: 12-88 pg/mL), bone-specific alkaline phosphatase (ALP) $(9-116 \mathrm{IU} / \mathrm{L})$, and 25(OH)D3 (30-100 $\mathrm{ng} / \mathrm{mL})$ levels in the patient and the control groups were analyzed using standard methods. In addition, C-reactive protein (CRP) with the nephelometric method (0.2-5.0 $\mathrm{mg} / \mathrm{L}$ ), erythrocyte sedimentation rate (ESR) with the Westergren method $(0-20 \mathrm{~mm} / \mathrm{h})$, serum total calcium, ionized calcium, urea, creatinine, phosphorous, total protein, and albumin levels were measured with the standard autoanalyzer. The vitamin D level was defined as deficient when $25(\mathrm{OH}) \mathrm{D}$ was $<20 \mathrm{ng} / \mathrm{mL} .^{[14,15]}$ The patients were divided into two groups according to $25(\mathrm{OH}) \mathrm{D}$ deficiency. Clinical, laboratory, and radiographic characteristics were analyzed between the two groups.

\section{Statistical analysis}

Statistical analysis was performed using the PASW version 18.0 software (SPSS Inc., Chicago, IL, USA). The Shapiro-Wilk test was used to for the normality test. According to the results, age, body mass index (BMI), and Lequesne variables were normally distributed. Non-parametric tests were used due to the unequal variances. Descriptive statistics were expressed in mean \pm standard deviation (SD), and median (min-max) for continuous variables. The Student's t-test was used to analyze significant differences for normal distribution between low $(<20$ $\mathrm{ng} / \mathrm{mL}$ ) and normal vitamin $\mathrm{D}$ groups, while the Mann-Whitney U test was used for the abnormally distributed variables. The chi-square and Fisher's exact tests were done to evaluate associations among categorical variables. Each of the JSN and osteophytes scores were divided into two groups: the first group consisted of Grade 1 and 2 scores, while the second group consisted of Grade 3 scores according to the OARSI Atlas Grading Scale. Variable selection was performed with univariate analysis and at least moderately significant variables (i.e., age, disease duration, BMI, and vitamin D) were selected for the multivariate logistic regression analysis. The Spearman correlation test was used to analyze relationships between the functional scores and continuous variables. Multiple linear regressions were also used to examine the association with risk factors and functional scores. The KOOS-PS and Lequesne scores were analyzed in male and female groups using the Mann-Whitney U test. A $p$ value of $<0.05$ was considered statistically significant.

\section{RESULTS}

The demographic and clinical characteristics of all patients are shown in Table 1 . Serum calcium, $\mathrm{PTH}$, and albumin levels were within normal limits in all patients. The mean value of $25(\mathrm{OH}) \mathrm{D}$ level was $13.4 \pm 10.6 \mathrm{ng} / \mathrm{mL}$, and 90 patients $(84.1 \%)$ were vitamin $\mathrm{D}$ deficient. Radiographic findings based on the OARSI Atlas Grading Scale revealed JSN in all 
Table 1. Demographic and clinical characteristics of patients with knee osteoarthritis

\begin{tabular}{|c|c|c|c|c|c|}
\hline & $\mathrm{n}$ & $\%$ & Mean \pm SD & Median & Min-Max \\
\hline Age (year) & & & $63.0 \pm 9.6$ & & \\
\hline \multicolumn{6}{|l|}{ Sex } \\
\hline Female & 90 & 84.1 & & & \\
\hline Male & 17 & 15.9 & & & \\
\hline Body mass index $\left(\mathrm{kg} / \mathrm{m}^{2}\right)$ & & & $31.4 \pm 6.1$ & & \\
\hline Duration of disease (month) & & & & 60 & $1-240$ \\
\hline Calcium (mmol/L) & & & & 9.60 & $7.70-78.00$ \\
\hline Vitamin D (ng/mL) & & & & 11.90 & $2.50-67.90$ \\
\hline Lequesne Index & & & $12.9 \pm 3.6$ & & \\
\hline KOOS-PS & & & & 40.30 & $14.80-62.00$ \\
\hline Visual Analog Scale-pain & & & & 7.00 & $4.00-10.00$ \\
\hline \multicolumn{6}{|l|}{ Kellgren-Lawrence Grade } \\
\hline 1 & 4 & 3.7 & & & \\
\hline 2 & 33 & 30.8 & & & \\
\hline 3 & 48 & 44.9 & & & \\
\hline 4 & 22 & 20.6 & & & \\
\hline \multicolumn{6}{|l|}{ OARSI-JSN } \\
\hline 1 & 22 & 20.6 & & & \\
\hline 2 & 52 & 48.6 & & & \\
\hline 3 & 33 & 30.8 & & & \\
\hline \multicolumn{6}{|l|}{ OARSI-osteophytes } \\
\hline 1 & 40 & 37.4 & & & \\
\hline 2 & 46 & 43.0 & & & \\
\hline 3 & 21 & 19.6 & & & \\
\hline
\end{tabular}

SD: Standard deviation; Min: Minimum; Max: Maximum; KOOS-PS: Knee Injury and Osteoarthritis Outcome Score-Physical Function Short-Form; OARSI: Osteoarthritis Research Society International Atlas.

Table 2. A comparison of the patients with and without vitamin D deficiency

\begin{tabular}{|c|c|c|c|c|c|c|c|c|c|c|c|}
\hline & \multicolumn{5}{|c|}{$\begin{array}{c}\text { Group } 1(\mathrm{n}=90) \\
(25(\mathrm{OH}) \mathrm{D}<20 \mathrm{ng} / \mathrm{mL})\end{array}$} & \multicolumn{5}{|c|}{$\begin{array}{c}\text { Group } 2(\mathrm{n}=17) \\
(25(\mathrm{OH}) \mathrm{D} \geq 20 \mathrm{ng} / \mathrm{mL})\end{array}$} & \multirow[b]{2}{*}{$p$} \\
\hline & $\mathrm{n}$ & $\%$ & Mean \pm SD & Median & Min-Max & $\mathrm{n}$ & $\%$ & Mean \pm SD & Median & Min-Max & \\
\hline Age (year) & & & $62.6 \pm 9.9$ & & & & & $65.0 \pm 7.5$ & & & 0.25 \\
\hline Sex & & & & & & & & & & & 0.46 \\
\hline Female & 75 & & & & & 15 & & & & & \\
\hline Male & 15 & & & & & 2 & & & & & \\
\hline Body mass index $\left(\mathrm{kg} / \mathrm{m}^{2}\right)$ & & & $31.7 \pm 6.0$ & & & & & $29.8 \pm 6.3$ & & & 0.37 \\
\hline Duration of disease (month) & & & & 48.00 & $3.00-240.00$ & & & & 60.00 & $1.00-240.00$ & 0.80 \\
\hline Lequesne Index & & & $12.9 \pm 3.5$ & & & & & $13.1 \pm 3.8$ & & & 0.65 \\
\hline KOOS-PS & & & & 39.45 & $14.80-62.00$ & & & & 40.30 & $14.80-62.00$ & 0.59 \\
\hline Visual Analog Scale-pain & & & & 7.00 & $4.00-10.00$ & & & & 7.00 & $4.00-9.00$ & 0.47 \\
\hline Kellgren-Lawrence Grade & & & & & & & & & & & 0.83 \\
\hline 1 & 3 & 3.3 & & & & 1 & 5.9 & & & & \\
\hline 2 & 27 & 30.0 & & & & 6 & 35.3 & & & & \\
\hline 3 & 42 & 46.7 & & & & 6 & 35.3 & & & & \\
\hline 4 & 18 & 20.0 & & & & 4 & 23.5 & & & & \\
\hline OARSI-JSN & & & & & & & & & & & 0.80 \\
\hline 1 & 18 & 20.0 & & & & 4 & 20.6 & & & & \\
\hline 2 & 45 & 50 & & & & 7 & 41.2 & & & & \\
\hline 3 & 27 & 30 & & & & 6 & 35.3 & & & & \\
\hline OARSI-osteophytes & & & & & & & & & & & 0.66 \\
\hline 1 & 32 & 35.6 & & & & 8 & 47.1 & & & & \\
\hline 2 & 40 & 44.4 & & & & 6 & 35.3 & & & & \\
\hline 3 & 18 & 20.0 & & & & 3 & 17.6 & & & & \\
\hline
\end{tabular}

SD: Standard deviation; Min: Minimum; Max: Maximum; KOOS-PS: Knee Injury and Osteoarthritis Outcome Score-Physical Function Short-Form; JSN: joint space narrowing; OARSI: Osteoarthritis Research Society International Atlas. 
Table 3. Multivariate logistic regression analysis showing the association between radiographic osteoarthritis and risk factors

\begin{tabular}{|c|c|c|c|c|c|c|}
\hline & B & SE & $p^{*}$ & $\operatorname{Exp}(B)$ & \multicolumn{2}{|c|}{$95 \% \mathrm{CI}$} \\
\hline \multicolumn{7}{|l|}{ JSN } \\
\hline \multicolumn{7}{|l|}{$2(\text { Grade } 3)^{\star \star}$} \\
\hline Intercept & -14.082 & 3.297 & 0.000 & & & \\
\hline Age & 0.131 & 0.034 & 0.000 & 1.140 & 1.066 & 1.218 \\
\hline Body mass index & 0.140 & 0.046 & 0.003 & 1.150 & 1.050 & 1.206 \\
\hline Vitamin D & -0.004 & 0.023 & 0.879 & 0.996 & 0.952 & 1.043 \\
\hline Disease duration & 0.006 & 0.004 & 0.168 & 1.006 & 0.998 & 1.014 \\
\hline \multicolumn{7}{|l|}{ Osteophytes } \\
\hline \multicolumn{7}{|l|}{$2(\text { Grade } 3)^{\star \star}$} \\
\hline Intercept & -8.537 & 2.851 & 0.003 & & & \\
\hline Age & 0.077 & 0.030 & 0.010 & 1.081 & 1.019 & 1.146 \\
\hline Body mass index & 0.072 & 0.045 & 0.107 & 1.075 & 0.985 & 1.174 \\
\hline Vitamin D & -0.029 & 0.032 & 0.360 & 0.971 & 0.912 & 1.034 \\
\hline Disease duration & 0.002 & 0.004 & 0.595 & 1.002 & 0.994 & 1.011 \\
\hline
\end{tabular}

patients, while JSN of Grade 2-3 was seen in 85 patients (79.4\%) and 67 patients (62.6\%) had severe osteophytes in the medial and lateral tibiofemoral compartments of both right and left knees. There was no significant difference in the age, BMI, duration of knee OA, function and radiographic grading between vitamin $\mathrm{D}$ deficient and normal groups (Table 2).

Risk factors for radiographic knee OA (OARSI-JSN and osteophytes) such as age, disease duration, $\mathrm{BMI}$, and $25(\mathrm{OH}) \mathrm{D}$ deficiency were analyzed using multivariate logistic regression analysis. A significant relationship was found between the JSN with age and BMI, while only age was found to be associated with osteophytes (Table 3). However, 25(OH)D levels were not associated with JSN or osteophytes in the multivariate logistic regression analyses.
Furthermore, the KOOS-PS and Lequesne scores used to assess the functional status were not found to be significantly different between the groups. The factors associated with the functional scores were analyzed using the correlation analysis and pain, BMI, disease duration, and age were found to be associated with both indices $(\mathrm{p}<0.05)$. However, there was no correlation between the vitamin $\mathrm{D}$ levels and functional scores. In the multiple linear regression analyses, on the other hand, there was an association between the functional scores and age, BMI, and pain (Table 4).

The KOOS-PS and Lequesne scores were analyzed in categories according to sex. Although the Lequesne scores were found to be worse in females, there was no significant difference. In addition, the mean Lequesne scores were $10.5 \pm 3.3$ (range 4 to 15 ) in males and

Table 4. Functional status of patients with risk factors based on the multiple linear regression analysis

\begin{tabular}{|c|c|c|c|c|c|c|}
\hline & B & SE & Standard B $(\beta)$ & $p$ & 959 & $\mathrm{CI}$ \\
\hline \multicolumn{7}{|l|}{ KOOS-PS } \\
\hline Constant & -25.206 & 9.494 & & 0.009 & -44.04 & -6.372 \\
\hline Age & 0.297 & 0.100 & 0.231 & $0.004^{*}$ & 0.098 & 0.495 \\
\hline Body mass index & 0.544 & 0.162 & 0.270 & $0.001^{\star}$ & 0.222 & 0.866 \\
\hline Vitamin D & 0.090 & 0.089 & 0.078 & 0.315 & -0.087 & 0.268 \\
\hline Disease duration & 0.008 & 0.016 & 0.038 & 0.628 & -0.024 & 0.040 \\
\hline Visual Analog Scale-pain & 3.964 & 0.602 & 0.511 & $0.000^{*}$ & 2.769 & 5.159 \\
\hline \multicolumn{7}{|l|}{ Lequesne } \\
\hline Constant & -7.265 & 2.821 & & 0.011 & -12.860 & -1.669 \\
\hline Age & 0.124 & 0.030 & 0.333 & $0.000^{*}$ & 0.065 & 0.183 \\
\hline Body mass index & 0.166 & 0.048 & 0.285 & $0.001^{*}$ & 0.071 & 0.262 \\
\hline Vitamin D & 0.028 & 0.027 & 0.084 & 0.295 & -0.025 & 0.081 \\
\hline Disease duration & 0.004 & 0.005 & 0.075 & 0.353 & -0.005 & 0.014 \\
\hline Visual Analog Scale-pain & 0.922 & 0.179 & 0.409 & $0.000^{*}$ & 0.567 & 1.277 \\
\hline
\end{tabular}

B: Regression coefficient; SE: Standard error; CI: Confidence interval; KOOS-PS: Knee Injury and Osteoarthritis Outcome Score-Physical Function Short-Form; ${ }^{*} \mathrm{p}<0.05$. 
13.4 \pm 3.4 (range 5 to 21$)$ in females $(p=0.003)$. The median KOOSPS scores was 40.30 (range 14.80 to 62.00 ) in males and 37.000 (range 14.80 to 54.40 ) in females $(\mathrm{p}=0.079)$.

\section{DISCUSSION}

Osteoarthritis is the most common form of arthritis, characterized by cartilage loss, thereby, leading to the functional failure. ${ }^{[16]}$ Vitamin D is a hormone which affects bone metabolism and non-bony tissues. The relationship between vitamin $\mathrm{D}$ and knee $\mathrm{OA}$ has been studied previously. In the literature, although there are studies supporting the effect of vitamin D deficiency on knee OA progression, no association has been reported in several studies. ${ }^{[5-7,16,17]}$ In this study, therefore, we investigated the effect of serum levels of $25(\mathrm{OH}) \mathrm{D}$ in patients with primary knee OA and assessed its association with the radiographic grading and functional status of the patients.

Vitamin D deficiency, which is defined as serum $25(\mathrm{OH}) \mathrm{D}$ levels of $<20 \mathrm{ng} / \mathrm{mL}$, has been reported with a rate ranging from 2.3 to $60 \%{ }^{[18-22]}$ Its prevalence varies according to the age and sex of the patient, ethnicity and geographical factors, and in those living in nursing homes. In the Turkish population, vitamin $\mathrm{D}$ deficiency ranges between 37.9 and $71.7 \%{ }^{[23-26]}$ In this study, the mean $25(\mathrm{OH}) \mathrm{D}$ level was $13.4 \pm 10.6$, and 90 patients $(84.1 \%)$ were vitamin $\mathrm{D}$ deficient, indicating a higher prevalence compared to previous studies conducted in Turkey. This result may be due to the high mean age of the patients, high rates of housewives included and of those living in the rural areas. In addition, the sun exposure may be inadequate, as the majority of the women wear long garments and headscarves.

Some hypotheses have been advocated about the influence of vitamin $\mathrm{D}$ level on the development or progression of $\mathrm{OA}$. Although the underlying mechanism still remains unclear, it is considered that vitamin $\mathrm{D}$ deficiency can affect the chondrocytes, the condition of articular cartilage, increasing the PTH and bone turnover. ${ }^{[17]}$ Furthermore, vitamin D stimulates the synthesis of proteoglycan by the mature articular cartilage and, thus, may affect the articular cartilage metabolism. ${ }^{[27]}$ However, several studies about vitamin $\mathrm{D}$ and $\mathrm{OA}$ relationship reveal controversial results. Heidari et al. ${ }^{[5]}$ reported that $25(\mathrm{OH}) \mathrm{D}$ was associated with symptomatic knee $\mathrm{OA}$ in patients aged $<60$ years. In a review including 15 studies, a moderate evidence was found indicating that low levels of $25(\mathrm{OH}) \mathrm{D}$ were associated with an increased progression of radiographic OA. ${ }^{[16]}$ In another study including 880 randomly-selected patients, low vitamin D levels were associated with JSN. ${ }^{[28]}$ Bergink et al. ${ }^{[17]}$ also evaluated 25(OH)D levels, dietary vitamin D intake, and radiographic $\mathrm{OA}$ in 1,248 patients and they reported higher JSN scores in the patients with vitamin D deficiency.

Although it is thought that vitamin D has an effect on chondrocytes and articular cartilage, several studies have shown no association between vitamin $\mathrm{D}$ status and the risk of cartilage loss and severity of radiographic knee OA grading. ${ }^{[6,7]}$ Muraki et al. ${ }^{[27]}$ reported that lower $25(\mathrm{OH}) \mathrm{D}$ levels might be associated with increased knee pain rather than radiographic changes. In another study including 1,644 female twins, the authors found no association between the JSN and vitamin D levels in the patients who had an evidence of increased bone turnover, increased PTH levels, and decreased vitamin D levels. ${ }^{[29]}$ In our study, radiographic X-ray grading was evaluated with two different methods (i.e., KellgrenLawrence and OARSI). Although the majority of the patients with knee OA had vitamin D deficiency, we found no relationship between vitamin $D$ levels and radiographic severity. However, age and BMI were found to affect the radiographic scores in our study.

Furthermore, functional disability is one of major public health problems in elderly population. Knee OA provides major contribution to the joint function and disability in the general population. ${ }^{[30]}$ Factors associated with disability in knee OA include age, low educational status, obesity, female sex, comorbidity, radiographic severity, and pain. ${ }^{[31]}$ The risk of disability also increases with the presence of knee pain. ${ }^{[30-32]}$ There are also several studies reporting a relationship between pain and physical functions in patients with knee OA. ${ }^{[30-32]}$ In previous studies, knee pain, age, and obesity were found more evident determinants of functional disability than the severity of radiographic knee OA. ${ }^{[30-32]}$ Consistent with the literature, we also found a positive correlation between the functional disability and pain severity, BMI, and age.

In recent years, the relationship between vitamin $\mathrm{D}$ deficiency and functional disability has been studied. ${ }^{[6,33-35]}$ Sanghi et al. ${ }^{[34]}$ suggested a slight, but statistically significant clinical benefit related to pain and function with vitamin $\mathrm{D}$ treatment in patients with knee OA. Glover et al. ${ }^{[35]}$ also demonstrated that the participants with adequate vitamin D had significantly less knee OA pain and better functional 
performance than those with vitamin $\mathrm{D}$ deficiency. However, Al-Jarallah et al. ${ }^{[6]}$ found no association between vitamin $\mathrm{D}$ and functional assessment in the patients with primary knee OA. Although functional status was evaluated with two different indices in the present study, we found no association between the functional scores and vitamin $\mathrm{D}$ levels. The higher mean age ( $>60$ years) and radiographic OA Grade in both of vitamin $\mathrm{D}$ insufficient and normal groups may have affected the functional disability, rather than vitamin $\mathrm{D}$ levels.

The small sample size and lack of a longitudinal assessment are the main limitations to this study.

In conclusion, our study results suggest that there is no association between vitamin D levels and severity of knee OA and functional status. Age and BMI are the main risk factors which affect the radiographic knee OA severity, while age, sex, BMI, and pain are the main determinants for the functional status.

\section{Declaration of conflicting interests}

The authors declared no conflicts of interest with respect to the authorship and/or publication of this article.

\section{Funding}

The authors received no financial support for the research and/or authorship of this article.

\section{REFERENCES}

1. Samuels J, Krasnokutsky S, Abramson SB. Osteoarthritis: a tale of three tissues. Bull NYU Hosp Jt Dis 2008;66:24450.

2. Kwan Tat S, Lajeunesse D, Pelletier JP, Martel-Pelletier J. Targeting subchondral bone for treating osteoarthritis: what is the evidence?Best Pract Res Clin Rheumatol 2010;24:51-70.

3. Fidan F, Alkan BM, Tosun A. Pandemic era: Vitamin $\mathrm{D}$ deficiency and insufficiency. Turkish Journal of Osteoporosis 2014; 20:71-4.

4. McAlindon TE, Felson DT, Zhang Y, Hannan MT, Aliabadi $\mathrm{P}$, Weissman B, et al. Relation of dietary intake and serum levels of vitamin D to progression of osteoarthritis of the knee among participants in the Framingham Study. Ann Intern Med 1996;125:353-9.

5. Heidari B, Heidari P, Hajian-Tilaki K. Association between serum vitamin $\mathrm{D}$ deficiency and knee osteoarthritis. Int Orthop 2011;35:1627-31.

6. Al-Jarallah KF, Shehab D, Al-Awadhi A, Nahar I, Haider $\mathrm{MZ}$, Moussa MA. Are 25(OH)D levels related to the severity of knee osteoarthritis and function? Med Princ Pract 2012;21:74-8.

7. Felson DT, Niu J, Clancy M, Aliabadi P, Sack B, Guermazi A, et al. Low levels of vitamin D and worsening of knee osteoarthritis: results of two longitudinal studies. Arthritis Rheum 2007;56:129-36.
8. Altman R, Asch E, Bloch D, Bole G, Borenstein D, Brandt $\mathrm{K}$, et al. Development of criteria for the classification and reporting of osteoarthritis. Classification of osteoarthritis of the knee. Diagnostic and Therapeutic Criteria Committee of the American Rheumatism Association. Arthritis Rheum 1986;29:1039-49.

9. Kellgren JH, Lawrence JS. Radiological assessment of osteoarthrosis. Ann Rheum Dis 1957;16:494-502.

10. Altman RD, Hochberg M, Murphy WA Jr, Wolfe F, Lequesne M. Atlas of individual radiographic features in osteoarthritis. Osteoarthritis Cartilage 1995;3:3-70.

11. D’Agostino MA, Conaghan P, Le Bars M, Baron G, Grassi W, Martin-Mola E, et al. EULAR report on the use of ultrasonography in painful knee osteoarthritis. Part 1: prevalence of inflammation in osteoarthritis. Ann Rheum Dis 2005;64:1703-9.

12. Lequesne MG. The algofunctional indices for hip and knee osteoarthritis. J Rheumatol 1997;24:779-81.

13. Gul ED, Yilmaz O, Bodur H. Reliability and validity of the Turkish version of the knee injury and osteoarthritis outcome score-physical function short-form (KOOS-PS). J Back Musculoskelet Rehabil 2013;26:461-6.

14. Cherniack EP, Florez H, Roos BA, Troen BR, Levis S. Hypovitaminosis D in the elderly: from bone to brain. J Nutr Health Aging 2008;12:366-73.

15. Holick MF. Vitamin D deficiency. N Engl J Med 2007;357:266-81.

16. Cao Y, Winzenberg T, Nguo K, Lin J, Jones G, Ding C. Association between serum levels of 25-hydroxyvitamin $\mathrm{D}$ and osteoarthritis: a systematic review. Rheumatology (Oxford) 2013;52:1323-34.

17. Bergink AP, Uitterlinden AG, Van Leeuwen JP, Buurman CJ, Hofman A, Verhaar JA, et al. Vitamin D status, bone mineral density, and the development of radiographic osteoarthritis of the knee: The Rotterdam Study. J Clin Rheumatol 2009;15:230-7.

18. Greene-Finestone LS, Berger C, de Groh M, Hanley DA, Hidiroglou N, Sarafin K, et al. 25-Hydroxyvitamin D in Canadian adults: biological, environmental, and behavioral correlates. Osteoporos Int 2011;22:1389-99.

19. Rodriguez A, Santa Marina L, Jimenez AM, Esplugues A, Ballester F, Espada M, et al. Vitamin D Status in Pregnancy and Determinants in a Southern European Cohort Study. Paediatr Perinat Epidemiol 2016;30:217-28.

20. Holick MF. High prevalence of vitamin D inadequacy and implications for health. Mayo Clin Proc 2006;81:353-73.

21. Santos MJ, Fernandes V, Garcia FM. Vitamin D Insufficiency in a Hospital Population: A Photograph from the Laboratory Perspective. Acta Med Port 2015;28:726-34. [Abstract]

22. Al-Faris NA. High Prevalence of Vitamin D Deficiency among Pregnant Saudi Women. Nutrients 2016;8:77.

23. Altınova AE, Aktürk M, Törüner F, Kaya M, Bukan N, Yetkin İ, et al. Tip 2 diyabetli hastalarda D vitamini eksikliği prevalansı ve CRP, fibrinojen, glisemik kontrol ve insülin direnci ile ilişkisi. Gazi Tıp Dergisi 2010;21:117-20.

24. Öztürk G, Bulut E, Akyol S, Taşlıpınar MY, Giniş Z,Uçar F, et al. The effect of serum $25(\mathrm{OH})$ vitamin $\mathrm{D}$ on hemogram parameters. Dicle Medical Journal 2014;40:332-4. 
25. Çolak AA, Doğan N, Bozkurt Ü, Avc1 R, Karademirci I. Vitamin D status in women in İzmir. Tepecik Eğit ve Araşt Hast Dergisi 2015;25:38-42.

26. Çidem M, Kara S, Hakan S, Özkaya M, Karacan İ. Prevalence and risk factors of vitamin D deficiency in patients with widespread musculoskeletal pain. Journal of Clinical and Experimental Investigations 2013;4:488-91.

27. Muraki S, Dennison E, Jameson K, Boucher BJ, Akune T, Yoshimura N, et al. Association of vitamin D status with knee pain and radiographic knee osteoarthritis. Osteoarthritis Cartilage 2011;19:1301-6.

28. Ding C, Cicuttini F, Parameswaran V, Burgess J, Quinn S, Jones G. Serum levels of vitamin D, sunlight exposure, and knee cartilage loss in older adults: the Tasmanian older adult cohort study. Arthritis Rheum 2009;60:1381-9.

29. Hunter DJ, Hart D, Snieder H, Bettica P, Swaminathan R, Spector TD. Evidence of altered bone turnover, vitamin D and calcium regulation with knee osteoarthritis in female twins. Rheumatology (Oxford) 2003;42:1311-6.

30. McAlindon TE, Cooper C, Kirwan JR, Dieppe PA. Determinants of disability in osteoarthritis of the knee. Ann Rheum Dis 1993;52:258-62.
31. Creamer P, Lethbridge-Cejku M, Hochberg MC. Factors associated with functional impairment in symptomatic knee osteoarthritis. Rheumatology (Oxford) 2000;39:490-6.

32. Jordan JM, Luta G, Renner JB, Linder GF, Dragomir A, Hochberg MC, et al. Self-reported functional status in osteoarthritis of the knee in a rural southern community: the role of sociodemographic factors, obesity, and knee pain. Arthritis Care Res 1996;9:273-8.

33. Mabey T, Honsawek S. Role of Vitamin D in Osteoarthritis: Molecular, Cellular, and Clinical Perspectives. Int J Endocrinol 2015;2015:383918.

34. Sanghi D, Mishra A, Sharma AC, Singh A, Natu SM, Agarwal S, et al. Does vitamin D improve osteoarthritis of the knee: a randomized controlled pilot trial. Clin Orthop Relat Res 2013;471:3556-62.

35. Glover TL, Goodin BR, King CD, Sibille KT, Herbert MS, Sotolongo AS, et al. A Cross-sectional Examination of Vitamin D, Obesity, and Measures of Pain and Function in Middle-aged and Older Adults With Knee Osteoarthritis. Clin J Pain 2015;31:1060-7. 